\title{
In vitro culture of rat hair follicle stem cells on rabbit bladder acellular matrix
}

\author{
Jia Li ${ }^{\dagger}$, Wenguang Wang ${ }^{\dagger}$, Hengqing An, Feng Wang, Mulati Rexiati and Yujie Wang ${ }^{*}$
}

\begin{abstract}
Background: The aim of this work was to create a xenogeneic cell scaffold complex with rabbit bladder acellular matrix and rat hair follicle stem cells, to study the feasibility of construct tissue engineer bladder through biocompatibility of hair follicle stem cells and heterogeneous bladder acellular matrix.

Material and Methods: New Zealand rabbit bladder acellular matrix was prepared. Scanning electron microscope and Masson staining were used to analyse the acellular material. Two-steps precipitation method was used to place the third generation of hair follicle stem cells onto the surface of the bladder acellular matrix. The in vitro cell growth on the scaffold complex was regularly monitored through an inverted microscope. Cell growth curve was established and histological examination and scanning electron microscopic were used to analyse the progresses of the cell growth on the matrix material.
\end{abstract}

Results: The prepared bladder acellular matrix was white, translucent and membranous. It possessed a fibrous network and collagen structure without any significant cell residues as displayed by the scanning electron microscope, and Masson staining. After $48 \mathrm{~h}$ of culture, observation by inverted microscope showed that the hair follicle stem cells grew well around the bladder acellular matrix. After 1 week of culture, scanning electron microscopy showed that the hair follicle stem cells spread and adhered on the surface of the scaffold.

Conclusions: The in vitro culture of rat hair follicle stem cells and the rabbit bladder acellular matrix possessed a good biocompatibility, which provides a good experiment support for hair follicle stem cells to repair the bladder defects disease.

Keywords: Hair follicle stem cells, Bladder acellular matrix, Biocompatibility, Culture

\section{Background}

Congenital malformations, inflammations, tumors and trauma can lead to the loss of bladder tissues structure or function, causing great suffering to the patients. In severe cases, they can lead to the decline in renal function and kidney failure. Usually, autologous nonurologic tissue or synthetic polymeric materials were used to repair or replace the bladder defect. However, since these materials cannot fully replace the function of the original tissues and organs, they can result in several adverse effects (Sumino and Mimata 2013; Xie

\footnotetext{
*Correspondence: huwenting7@163.com

${ }^{\dagger}$ Jia Li and Wenguang Wang contributed equally to this work Department of Urology, The First Affiliated Hospital of Xinjiang Medical University, Address: No. 137, Liyushan Road, Urumqi, Xinjiang Uygur Autonomous Region, China
}

et al. 2015; Kulikov et al. 2015; Alberti 2013; Vahabi and Drake 2015). Moreover, the limited resource of autological non-urologic tissues represents an additional obstacle. Bladder acellular matrix is a natural extracellular biomaterial which retains only the low antigenic substances including, but not limited to collagen, proteoglycan and glycoprotein. Therefore, xenogenic bladder acellular matrix used as a scaffold for bladder tissue engineering became the focus of the medical research (Liu et al. 2010; Corona et al. 2014). In this experiment, rat hair follicle stem cells, which possess the potential to differentiate into urinary tract epithelial cells and smooth muscle cells (Najafzadeh et al. 2013), were used to create a cell/scaffold complex in vitro. Thus, our present study may provide a useful alternative for bladder repair. The experiments were conducted from August 
2015 to October 2015 in the Clinical Research Institute of the First Affiliated Hospital of Xinjiang Medical University.

\section{Methods \\ Experimental animals}

Five males and females SD rats, weighing approximately 200 g, 1.5 months of age, and two New Zealand rabbits, 3-5 months of age, weighing approximately $2.5 \mathrm{~kg}$, were provided by the Animal Center of Xinjiang Medical University. The experiment was approved by the Animal Ethics Committee of the First Affiliated Hospital of Xinjiang Medical University (Approval Number: IACUC-20150707002).

\section{Reagents}

Masson stain Kit (Jiangcheng Corporation, China), trypsin and EDTA digestion solution (Solarbio Corporation, China), Dispase II (Roche Corporation, Switzerland), top grade fetal bovine serum (Sijiqing Corporation, China), K-SFM culture media (Gibco Corporation, USA), type IV collagen (Sigma Corporation, USA).

\section{Experimental methods}

\section{Rabbit bladder acellular matrix preparation}

The rabbit was sacrificed by air embolism. An incision in the abdominal midline was made, the bladder was removed and the fat and the fascia tissue around the bladder were removed. The bladder was rinsed 3 times in D-Hank's buffer containing $10 \%$ streptomycin, and then stored at $4{ }^{\circ} \mathrm{C}$ in D-Hank's buffer. The bladder wall was incised longitudinally with the mucous membrane side up. A blade was used to carefully remove the mucous membrane and the submucosa layer was removed under the microscope. The submucosa layer was cut into $1 \times 1 \mathrm{~cm}$ size pieces and washed 3 times with sterile PBS. The tissues were soaked and stirred in $100 \mathrm{~mL}$ PBS containing $0.1 \%$ sodium azide at $250 \mathrm{rpm} / \mathrm{min}$ at room temperature overnight. Next, the tissues were rinsed with sterile PBS and placed in $100 \mathrm{~mL}$ of $0.5 \mathrm{mmol} / \mathrm{L}$ EDTA $+0.4 \%$ trypsin solution, and stirred at $250 \mathrm{rpm} /$ min at $37^{\circ} \mathrm{C}$ for $5-6 \mathrm{~h}$ for digestion. Subsequently, they were rinsed with sterile PBS and placed in $100 \mathrm{~mL}$ of $1 \mathrm{~mol} / \mathrm{L} \mathrm{NaCl}$ solution containing DNase-I $4000 \mathrm{kU}$ and stirred at $250 \mathrm{rpm} / \mathrm{min}$ at $37{ }^{\circ} \mathrm{C}$ for $6-8 \mathrm{~h}$ to completely digest the cells and release the cell components. The tissues were placed in $100 \mathrm{~mL}$ solution containing $4 \%$ sodium deoxycholate and $0.1 \%$ sodium azide and stirred at $250 \mathrm{rpm} / \mathrm{min}$ at room temperature for $6-8 \mathrm{~h}$ to dissolve the bilayer lipid cell membrane and the intracellular lipid membranes. They were rinsed 3 times in sterile PBS containing $5 \%$ penicillin-streptomycin and placed flat into the well of a 24-well plate. The plate was placed in a vacuum freeze dryer for $6 \mathrm{~h}$. The freeze-dried bladder acellular matrix was sterilized by cobalt- 60 radiation with radiation dose of $25 \mathrm{kGy}$ and stored at $4{ }^{\circ} \mathrm{C}$. Scanning electron microscope and Masson staining were used for the observation of the de-cellular effect of the bladder acellular matrix.

\section{Rat hair follicle stem cell culture}

Single hair follicle tissue from SD rat whisker skin was dissected using microforceps under the microscope. The separated hair follicle tissues were placed in $0.25 \mathrm{~g} / \mathrm{L}$ Dispase II and digested for $2 \mathrm{~h}$ at $37^{\circ} \mathrm{C}$ on a shaker. The tissues were rinsed 3 times with PBS and were digested in a 1:1 solution of trypsin $(2.5 \mathrm{~g} / \mathrm{L})$ and EDTA $(0.2 \mathrm{~g} / \mathrm{L})$ for $1 \mathrm{~h}$ at $37{ }^{\circ} \mathrm{C}$ on the shaker. After filtration using a 200 mesh steel sieve, the mixture was centrifuged at $1500 \mathrm{rpm} / \mathrm{min}$ for $10 \mathrm{~min}$. The supernatant was removed and the cells were re-suspended in $10 \%$ fetal bovine serum and serum-free Keratinocytes medium. The cells were placed in collagen IV coated flasks, and stored in an incubator for $30 \mathrm{~min}$. The non-adherent cells were removed. The remaining cells were stored in the incubator at $37{ }^{\circ} \mathrm{C}$ with $5 \% \mathrm{CO}_{2}$. The culture medium was changed once every 2-3 days until the cells reached 70-80 \% confluence. Trypsin/EDTA was used to passage the cells to new flasks. The third generation of hair follicle stem cells were collected after days 5, washed with PBS, and divided into several fractions of $5 \times 105$ cells $/ 100 \mu \mathrm{L}$. Each sample was measured in triplicate. PE-labeled anti-CD34, and FITC-labeled anti-CD29 were added into the suspension to a final concentration of $5 \mu \mathrm{g} / \mathrm{mL}$ and incubated for $30 \mathrm{~min}$ at $4{ }^{\circ} \mathrm{C}$ in the dark. The cells were washed with PBS twice and analyzed by flow cytometry. Fluorescence-labeled IgG isotypes were used as the control. The hair follicle stem cells were identified after morphological observation and analysis of specific surface markers. Inverted microscope was used for the cell morphology observation of the hair follicle stem cells. Flow cytometry was used to identify CD34 and $\beta 1$ integrin (CD29) expression.

\section{In vitro co-culture of the hair follicle stem cells and the bladder acellular scaffold}

The prepared rabbit bladder acellular matrix was rinsed with sterile D-Hank's buffer 3 times and K-SFM medium was added to pre-wet the matrix for $24 \mathrm{~h}$. The K-SFM medium was removed and the prepared bladder was kept in plane condition. K-SFM medium containing $10 \%$ of fetal bovine serum was added to the prepared bladder to pre-wet it for $2 \mathrm{~h}$. Third generation of hair follicle stem cells were cultured in complete K-SFM medium containing $10 \%$ of fetal bovine serum at $37^{\circ} \mathrm{C}$ 
with $5 \% \mathrm{CO}_{2}$ until the cells were $80 \%$ confluent. Cells were digested using $0.125 \%$ trypsin/0.01 \% EDTA. Cells were counted and $1 \times 10^{9} / \mathrm{L}$ cells were suspended in complete K-SFM medium containing $10 \%$ fetal bovine serum. Subsequently, $0.5 \mathrm{~mL}$ cell suspension was slowly added to each well, pointing the pipette tip to the center of the 24-well plate containing the pre-wetted scaffold. Same amount of cell suspension was added to an empty well as control. The plate was incubated at $37^{\circ} \mathrm{C}$ with $5 \% \mathrm{CO}_{2}$ for $30 \mathrm{~min}$, and then $0.5 \mathrm{~mL}$ cell suspension was additionally added to each well and incubated for additional $30 \mathrm{~min}$. Next, $1 \mathrm{~mL}$ complete K-SFM containing $10 \%$ fetal bovine serum was added and the plate was incubated at $37{ }^{\circ} \mathrm{C}$ with $5 \% \mathrm{CO}_{2}$. From the second day onward of the in vitro co-culture of the cell/scaffold complex, cells from 4 randomly selected wells were counted following digestion with $0.125 \%$ trypsin $/ 0.01 \%$ EDTA and centrifugation. The cell counting was made for 10 subsequent days. The cell growth curve was plotted and compared with the control growth curve. Inverted phase contrast microscopy, scanning electron microscopy and histology were used for the morphology observation of the cell/scaffold complex and to plot the cell growth curves.

\section{Results}

\section{Structural features of the bladder acellular matrix}

The prepared bladder acellular matrix was white translucent and membranous, with a thickness of approximately $0.5 \mathrm{~mm}$ and possessed a certain elasticity and toughness. The bladder acellular matrix formed a sheet as a consequence of rehydration after lyophilisation, but wrinkles appeared when it was not immersed in the solution. Scanning electron microscope showed that the bladder acellular scaffold possessed a reticular fiber structure made of collagen with visible irregular voids, and no cell residues on the surface (Fig. 1). Masson staining of the bladder acellular matrix showed a thin layer of homogeneous blue-staining of collagen fibers with no residual cells (Fig. 2).

\section{Hair follicle stem cells culture and identification}

The hair follicle stem cells were small, polygon shaped and adherent after $48 \mathrm{~h}$ culture, as well as surrounded by some fibroblast cells. High purity hair follicle stem cells were obtained thanks to their ability of fast adhesion to collagen IV during cell passage compared to the fibroblasts. The third generation of hair follicle stem cells can reach $100 \%$ confluence after 7 days of culture (Fig. 3). The expressions of CD34 and $\beta 1$ integrin (CD 29) of the third generation of the hair follicle stem cells were increased after 5 days of culture (Fig. 4).

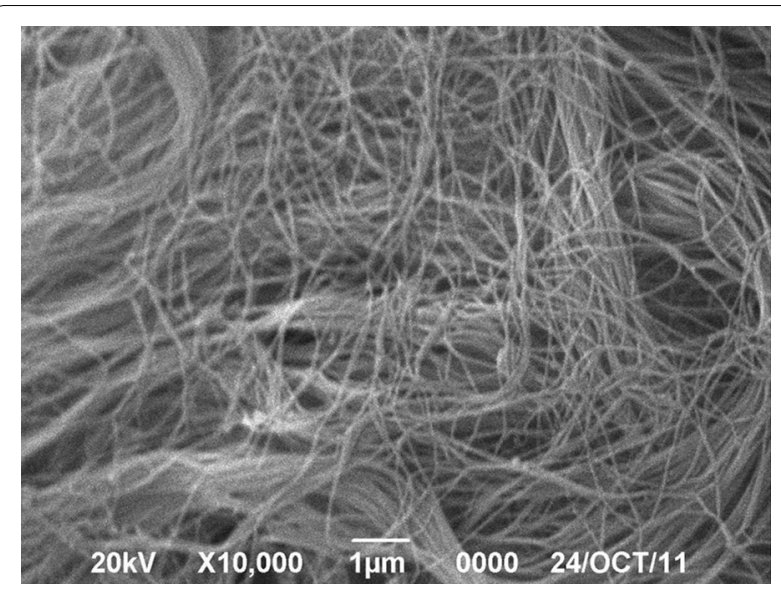

Fig. 1 Scanning electron microscopy demonstrated the bladder acellular matrix had fiber mesh structure, but no residual cells $(\times 10$ 000)

In vitro co-culture of the hair follicle stem cells and bladder acellular matrix

Two hours after the second inoculation of the hair follicle stem cells, inverted phase contrast microscopy showed a large amount of round or oval shaped cells adhering

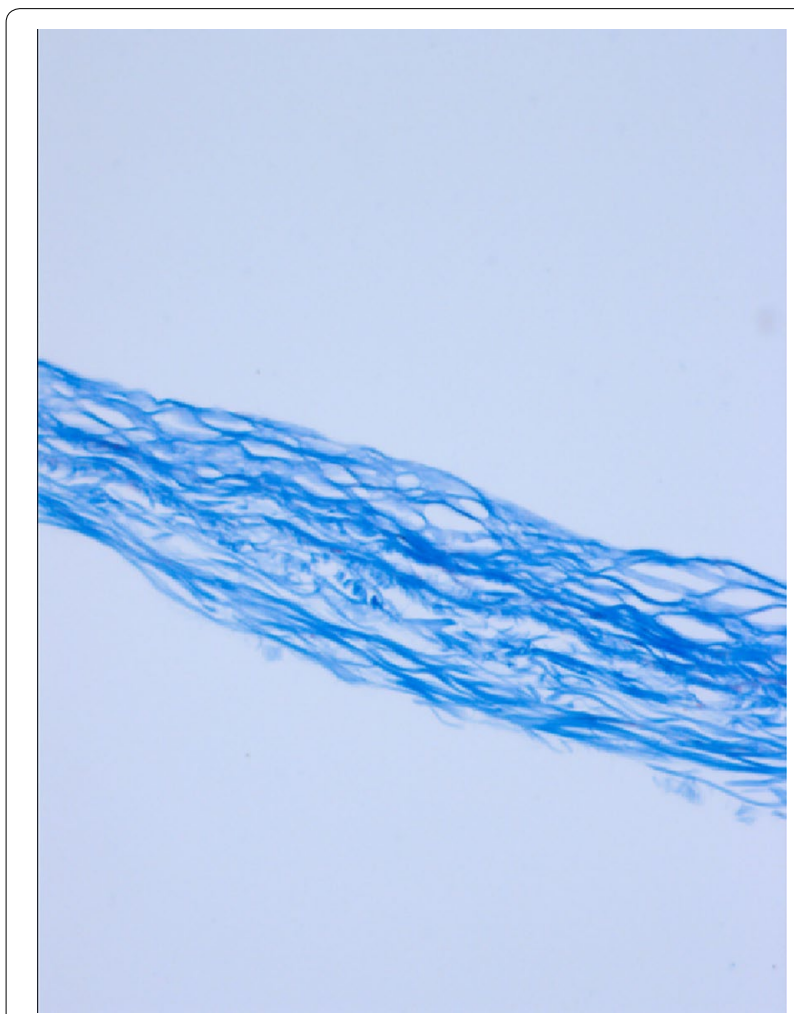

Fig. 2 Masson staining showed the bladder acellular matrix presented with loose blue collagen fiber structure, and had no residual cells $(\times 200)$ 


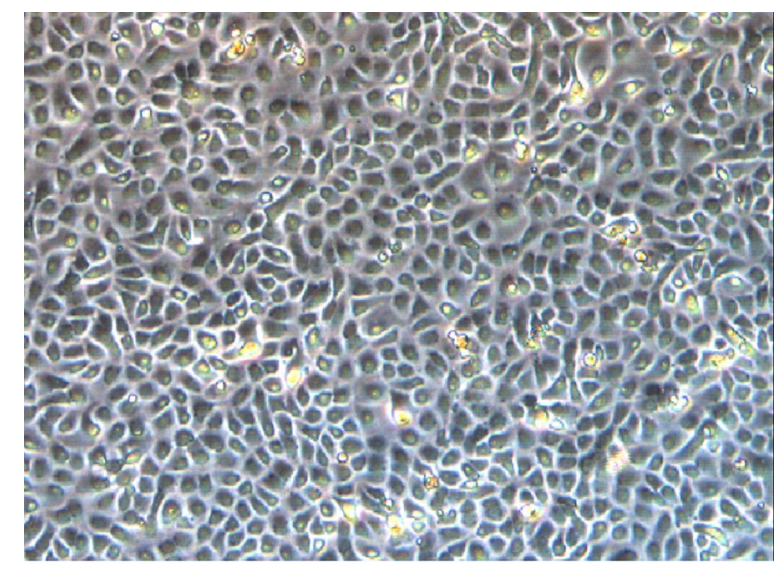

Fig. 3 Passage 3 hair follicle stem cells cultured for $7 \mathrm{~d}$ showed a typical "aura" shape under the microscope $(\times 50)$

on the scaffold and the surrounding areas at the bottom of the culture flask. Inverted phase contrast microscope showed a spindle shape and the same alignment direction of the cells adhered on the scaffold after $48 \mathrm{~h}$ of culture. The cells surrounding the scaffold were in good conditions and forming the typical "paving stone" (Fig. 5). After $48 \mathrm{~h}$ of co-culture of the cell/scaffold complex in vitro, the cells showed a plump morphology and they formed a monolayer on the surface of the scaffold as observed under the scanning electron microscope. The cells and the scaffold adhered tightly as a result of the matrix secreted by the cells, as well as the adhesion between cells (Fig. 6).

\section{Cell growth curve of the cell/scaffold complex}

The growth curves of the experimental group and the control group were basically the same,There was no statistical difference between the two groups $(P>0.05)$. Plateau phase was reached $7-8$ days after the cell inoculation, indicating that the cells grew well on the scaffold surface and possessed a great biocompatibility (Table 1; Fig. 7). After 7 days of culture with fresh K-SFM complete media replacement every $48 \mathrm{~h}$, the in vitro co-cultured cell/scaffold complex was fixed by paraformaldehyde and stained by Masson staining and observed under the light microscope. One to three layers of cells could be seen to adhere on the surface of the scaffold (Fig. 8).

\section{Discussion}

With the development of tissue engineering in recent years, the superiority of the bladder acellular matrix over other biological material has been demonstrated in a variety of experiments (Pokrywczynska et al. 2015; Zhao et al. 2015). The major advantages of the bladder acellular matrix are several: (1) The three-dimensional growth of the bladder acellular matrix is extremely similar to the original growth environment of the growth of the bladder. It represents a suitable environment for cell adhesion, growth, and connection between cells. (2) The degradation and absorption rates of the bladder acellular matrix match the regeneration of the bladder tissue. (3) The surface chemical properties are suitable for cell adsorption, growth and differentiation. (4) The removal of the antigen-containing cellular components leaves only the low antigenic materials such as collagen,
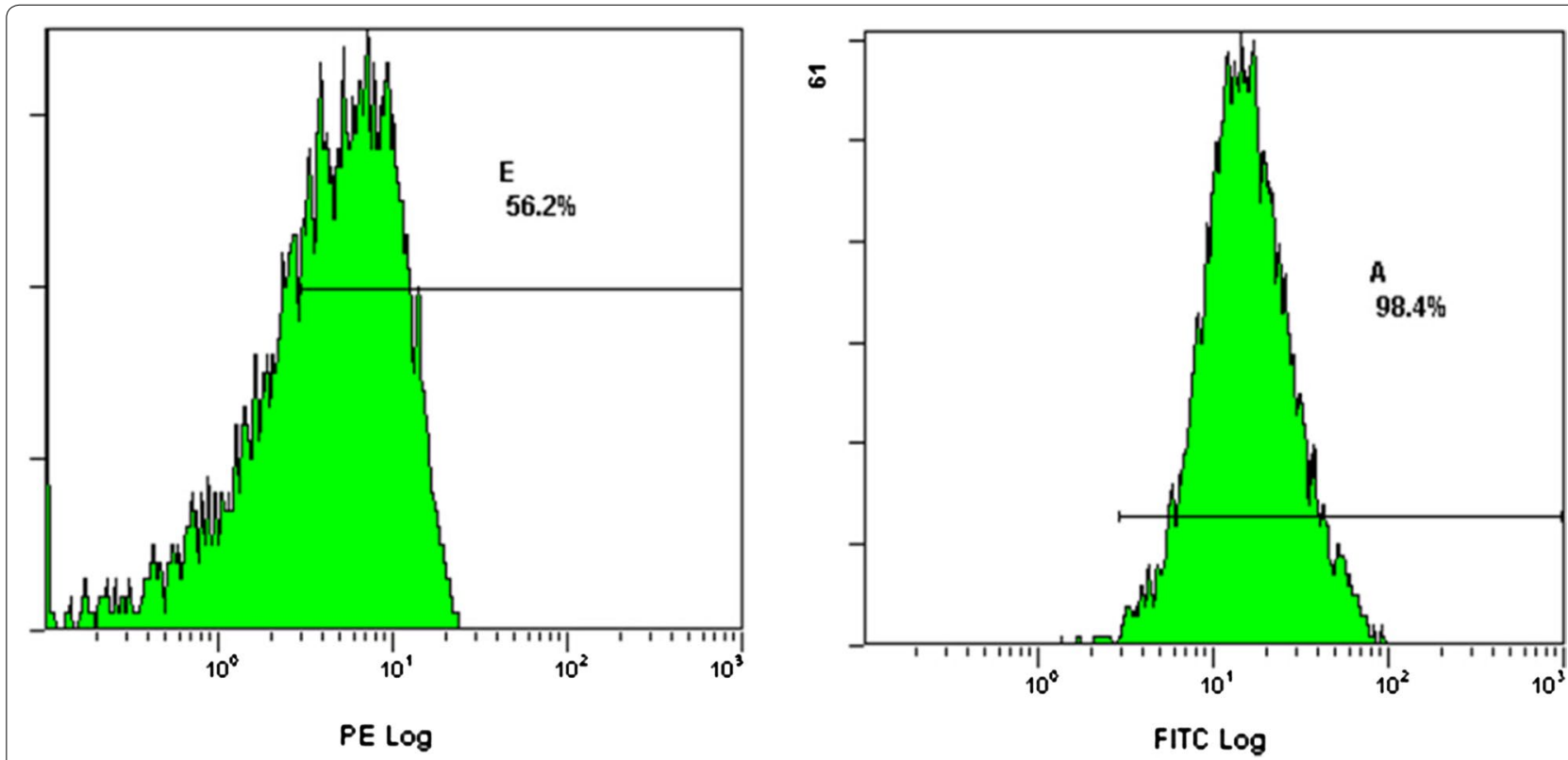

Fig. 4 PE-labeled CD34 and FITC-labeled $\beta 1$ integrin (CD29) of passage 3 hair follicle stem cells showed high expression 


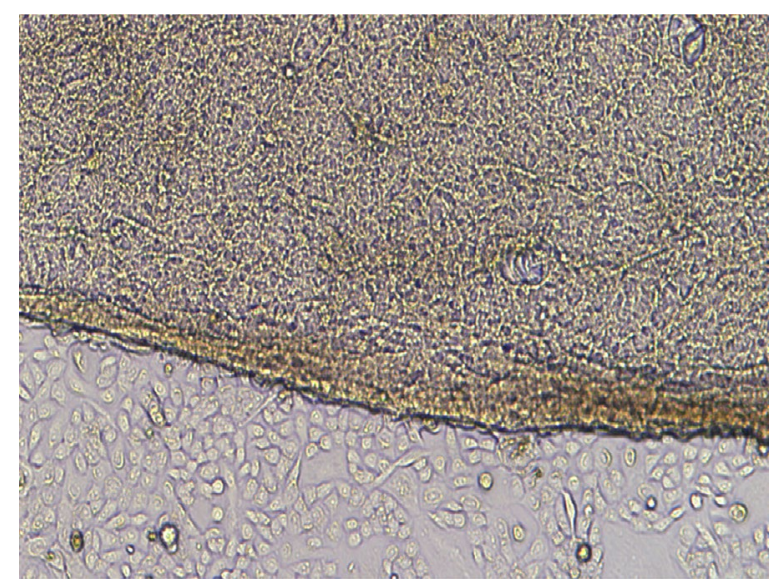

Fig. 5 Morphology of co-cultured hair follicle stem cells with bladder acellular matrix at $48 \mathrm{~h}$ observed under inverted phase contrast microscope $(\times 50)$

proteoglycans, glycoproteins, which can prevent graft rejection after transplant and provide a scaffold for the regeneration of the bladder mucosa, muscles, blood vessels, and nerves (Chun et al. 2015; Song et al. 2014; Xiong et al. 2015). Atala et al. (2006) was the first reporting the usage of tissue engineered bladder in clinical research in 2006. This study is considered as the landmark in bladder reconstruction surgery by many researchers. The studies by Yang et al. (2010) suggested that bladder acellular matrix contains a variety of functional tissue regeneration and wound healing growth factors, including fibroblast growth factors (FGF), transforming growth factor $\beta$ (TGF- $\beta$ ) and vascular endothelial growth factor (VEGF). These growth factors may play important roles in inducing the differentiation of stem cells into target cells. Subjected normal pig bladder to low permeability, repeated $80{ }^{\circ} \mathrm{C}$ freezing and thawing, DNase and RNase digestions and $\mathrm{NaOH}$ fragmentation method to prepare bladder acellular submucosa. The prepared bladder acellular submucosa showed a well-preserved structure and good biocompatibility. The results proved that the pig bladder submucosa could be used as a substitute material for tissue engineering repair (Lin et al. 2014).

Hair follicle stem cells are located at the hair follicle bulge and possess multi-directional differentiation ability. Through proliferation and differentiation, the stem cells can generate various cells to fulfill the organism's need. The study of hair follicle stem cell was further developed since the cell marker CD34, K15 and the $\beta 1$ integrin were identified. Compared with other adult stem cells, hair

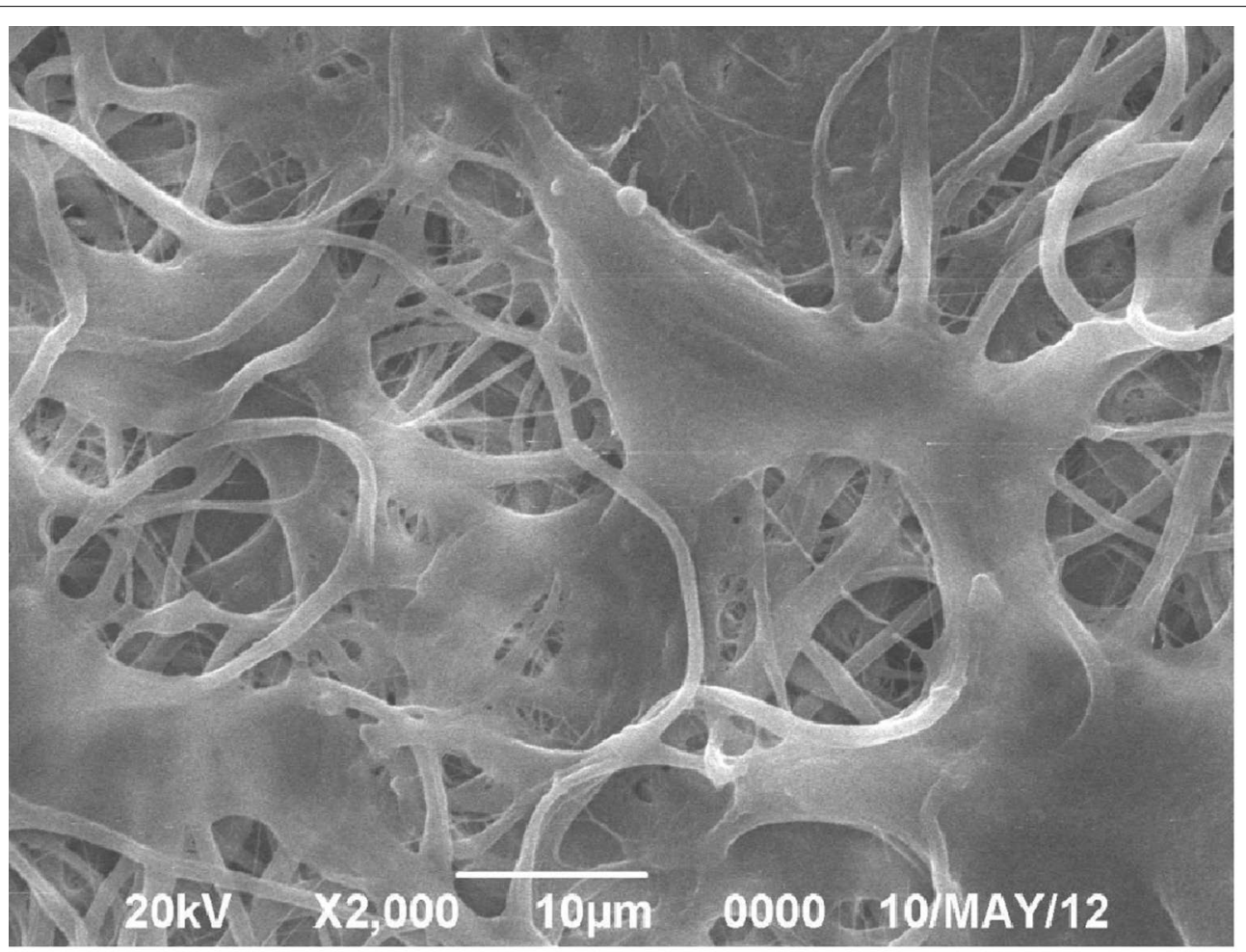

Fig. 6 Morphology of co-cultured hair follicle stem cells with bladder acellular matrix at $48 \mathrm{~h}$ observed under scanning electron microscope $(\times 1000)$ 
Table 1 Statistical analyses for cell growth of the composite material

\begin{tabular}{|c|c|c|c|c|c|c|c|c|c|c|c|c|}
\hline$t / d$ & 1 & 2 & 3 & 4 & 5 & 6 & 7 & 8 & 9 & 10 & 11 & 12 \\
\hline Experiment group (cell number/10 & 1.00 & 1.08 & 1.22 & 2.16 & 2.81 & 3.83 & 5.69 & 5.79 & 5.01 & 4.22 & 3.58 & 3.01 \\
\hline Control group (cell number/106) & 1.00 & 1.10 & 1.27 & 2.20 & 3.18 & 3.94 & 5.71 & 5.46 & 4.66 & 3.90 & 3.13 & 2.37 \\
\hline$p$ & & 0.94 & 0.90 & 0.94 & 0.47 & 0.71 & 0.98 & 0.50 & 0.33 & 0.46 & 0.32 & 0.22 \\
\hline
\end{tabular}

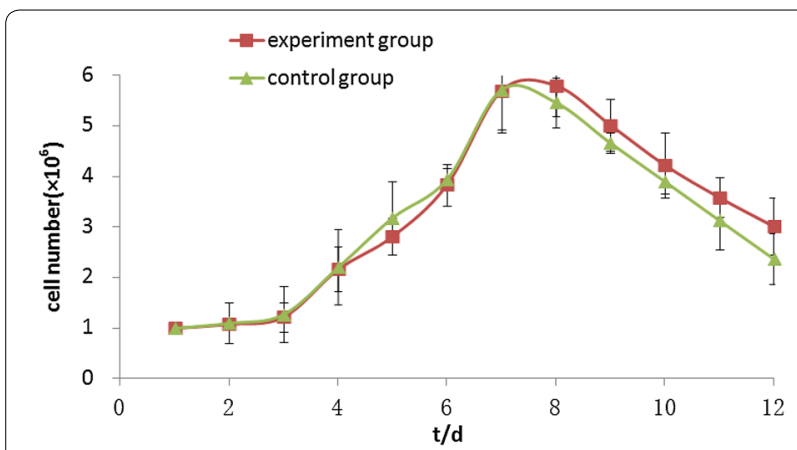

Fig. 7 Cell growth curve of the composite material

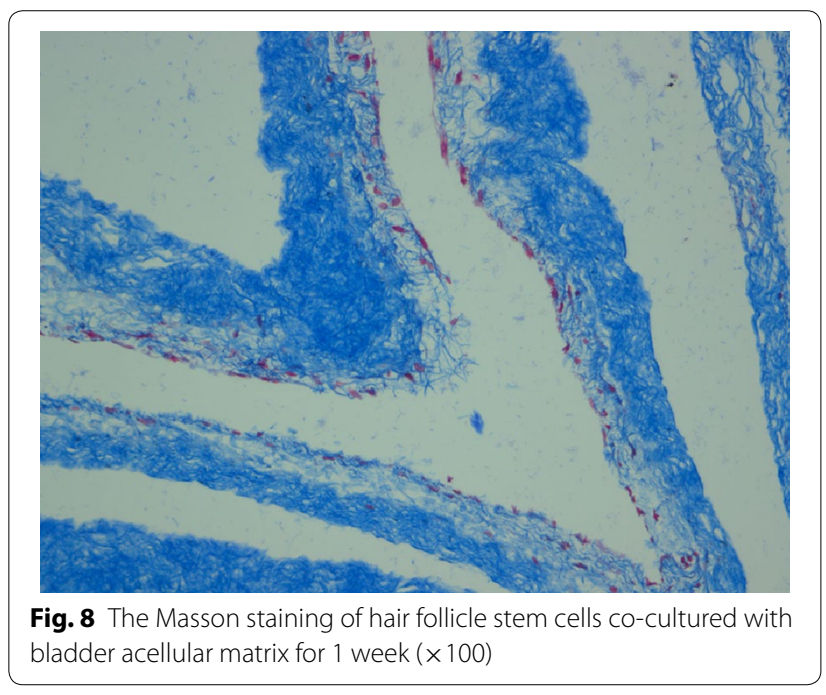

follicle stem cells have the following advantages: they are abundant, located on the surface thus easy to obtain, non-invasive, short growth cycle, and easy to expand. Hair follicle stem cells have been proved to be an excellent resource in regenerative medicine (Garza et al. 2011; Xu et al. 2013; Gola et al. 2012). Drewa et al. (2009) have implanted the rat hair follicle stem cells on the bladder acellular matrix and transplanted them back to rats with bladder wall defects to observe the bladder regeneration. The results showed that the bladder capacity was similar to the normal bladder capacity, and the shape of the bladder was regular. However, the safety of using hair follicle stem cells and related induction mechanisms need to be further studied.

The experiment methods used for the preparation of the bladder acellular matrix were based on the methods by Zhou et al. (2013) with slight modifications: microdissection was used combined with chemical decellularization, and subsequent improvements from trial and error were provided. Reagents such as sodium azide, sodium deoxycholate, DNase-I were used for the decellularization of the bladder submucosa. No trace of cells was found by scanning electron microscopy and histological tests. The complete decellularization effect can be achieved using this method several times (Hou et al. 2016). However, some of the chemical reagents used for decellularization are cytotoxic, such as the inorganic toxic sodium azide. When tissues are soaked in it for a long time, a small trace could remain into the tissue, compromising the subsequent cell adhesion and growth. Several experiments showed that cell growth and amplification efficiency are good in the groups with repeated PBS rinsing of the stem cells. Therefore, during the decellularization process, repeated PBS rinsing is essential for the preparation of the scaffold.

According to our own experimental conditions and long-term repeated experiments, a secondary sedimentation method was used, where cells were seeded on the scaffold $20 \mathrm{~min}$ after the first inoculation. The purpose of this method was to ensure that cells can be evenly distributed on and adhere to the scaffold, and to allow a penetration into the scaffold material. Tissue sectioning and staining showed that, while some cells penetrated into the scaffold, a large number of cells were still located on the surface of the scaffold. This was because cells were suspended on the surface of the scaffold material during static inoculation. Some cells diffused into the material with the diffusion of the liquid, but this passive inward movement is limited. Most cells were still stacked on the surface of the scaffold material by gravity, resulting in a large amount of cells attached to the surface and very few cells inside the scaffold. Because of the small size of the scaffold, the suspension volume used for static inoculation was only $1-2 \mathrm{~mL}$. In order to get a higher seeding density, the concentration of the suspensions should be increased, but high concentration of cell suspension could easily lead to cell aggregation, which would block 
scaffold pores and prevent cells from penetrating the scaffold. As a result of the limited contact sites on the scaffold, many cells were loosely attached on the surface of the scaffold. These cells could easily detach when cultural medium was added and therefore, the inoculation rate decreased when the inoculation concentration increased. After careful consideration of both aspects and repeated experimentations, an inoculation concentration of $1 \times 10^{9} / \mathrm{L}$ was used, and the results were satisfactory by histological examination.

\section{Conclusions}

The growth curves of the experimental group and the control group were basically the same. Plateau phase was reached 7-8 days after the cell inoculation, indicating that the cells grew well on the scaffold surface and possessed a great biocompatibility. The experimental results showed that hair follicle stem cells and the xenogenic bladder acellular matrix have good biocompatibility, providing a favorable experimental basis for further differentiation. Additional exogenous inducing factors should be analysed for the promotion of the regeneration of the urinary tract epithelial cells, smooth muscle cells, vascular and neural tissues during the induced differentiation process of the hair follicles stem cells on the xenogenic bladder acellular matrix. Specific dosage and methods also need further investigation. The mechanism of the differentiation of the hair follicles stem cells induced by the bladder acellular matrix will be the focus of further research.

\section{Authors' contributions}

$J$, WW and YW designed the study; $J$, HA, FW, and MR performed the experiments; JL, WW and YW wrote the paper; JL, WW, HA, FW, MR and YW reviewed and edited the manuscript. All authors read and approved the final manuscript.

\section{Acknowledgements}

This work was supported by the natural science foundation of Xinjiang Uygur Autonomous Region (No. 2015211C090).

\section{Competing interests}

The authors declare that they have no competing interests.

Received: 24 February 2016 Accepted: 24 August 2016

Published online: 31 August 2016

\section{References}

Alberti C (2013) Tissue engineering as innovative chance for organ replacement in radical tumor surgery. Eur Rev Med Pharmacol Sci 17:624-631

Atala A, Bauer SB, Soker S, Yoo JJ, Retik AB (2006) Tissue-engineered autologous bladders for patients needing cystoplasty. Lancet 367:1241-1246
Chun SY, Kim BS, Kwon SY et al (2015) Urethroplasty using autologous urethral tissue-embedded acellular porcine bladder submucosa matrix grafts for the management of long-segment urethral stricture in a rabbit model. J Korean Med Sci 30:301-307

Corona BT, Ward CL, Baker HB, Walters TJ, Christ GJ (2014) Implantation of in vitro tissue engineered muscle repair constructs and bladder acellular matrices partially restore in vivo skeletal muscle function in a rat model of volumetric muscle loss injury. Tissue Eng Part A 20:705-715

Drewa T, Joachimiak R, Kaznica A, Sarafian V, Pokrywczynska M (2009) Hair stem cells for bladder regeneration in rats: preliminary results. Transplant Proc. 41(10):4345-4351

Garza LA, Yang CC, Zhao T et al (2011) Bald scalp in men with androgenetic alopecia retains hair follicle stem cells but lacks CD200-rich and CD34positive hair follicle progenitor cells. J Clin Invest 121:613-622

Gola M, Czajkowski R, Bajek A, Dura A, Drewa T (2012) Melanocyte stem cells: biology and current aspects. Med Sci Monit 18:RA155-9

Hou X, Shi C, Chen W, Chen B, Jia W et al (2016) Transplantation of human adipose-derived mesenchymal stem cells on a bladder acellular matrix for bladder regeneration in a canine model. Biomed Mater 11(3):031001

Kulikov DA, Kulikov AV, Arkhipova LV et al (2015) Effects of allogenic fetal pancreatic tissue transplantation on regeneration of islet cells in recipient rats with alloxan-induced diabetes mellitus. Bull Exp Biol Med 158:361-363

Lin HK, Godiwalla SY, Palmer B et al (2014) Understanding roles of porcine small intestinal submucosa in urinary bladder regeneration: identification of variable regenerative characteristics of small intestinal submucosa. Tissue Eng Part B Rev 20:73-83

Liu JY, Peng HF, Gopinath S, Tian J, Andreadis ST (2010) Derivation of functional smooth muscle cells from multipotent human hair follicle mesenchymal stem cells. Tissue Eng Part A 16:2553-2564

Najafzadeh N, Nobakht M, Pourheydar B, Golmohammadi MG (2013) Rat hair follicle stem cells differentiate and promote recovery following spinal cord injury. Neural Regen Res 8:3365-3372

Pokrywczynska M, Gubanska I, Drewa G, Drewa T (2015) Application of bladder acellular matrix in urinary bladder regeneration: the state of the art and future directions. Biomed Res Int 2015:613439

Song L, Murphy SV, Yang B, Xu Y, Zhang Y, Atala A (2014) Bladder acellular matrix and its application in bladder augmentation. Tissue Eng Part B Rev 20:163-172

Sumino Y, Mimata H (2013) Regenerative medicine as a new therapeutic strategy for lower urinary tract dysfunction. Int J Urol 20:670-675

Vahabi B, Drake MJ (2015) Physiological and pathophysiological implications of micromotion activity in urinary bladder function. Acta Physiol (Oxf) 213:360-370

Xie D, Shang C, Zhang H, Guo Y, Tong X (2015) Up-regulation of miR-9 target CBX7 to regulate invasion ability of bladder transitional cell carcinoma. Med Sci Monit 21:225-230

Xiong Q, Lin H, Hua X et al (2015) A nanomedicine approach to effectively inhibit contracture during bladder acellular matrix allograft-induced bladder regeneration by sustained delivery of vascular endothelial growth factor. Tissue Eng Part A 21:45-52

Xu ZC, Zhang Q, Li H (2013) Human hair follicle stem cell differentiation into contractile smooth muscle cells is induced by transforming growth factor- $\beta 1$ and platelet-derived growth factor BB. Mol Med Rep $8: 1715-1721$

Yang B, Zhang Y, Zhou L et al (2010) Development of a porcine bladder acellular matrix with well-preserved extracellular bioactive factors for tissue engineering. Tissue Eng Part C Methods 16:1201-1211

Zhao Y, He Y, Guo JH et al (2015) Time-dependent bladder tissue regeneration using bilayer bladder acellular matrix graft-silk fibroin scaffolds in a rat bladder augmentation model. Acta Biomater 23:91-102

Zhou L, Yang B, Wang P et al (2013) Local and systemic safety evaluation of regenerated rabbit bladder repaired with xenogeneous bladder acellular matrix. Zhongguo Xiu Fu Chong Jian Wai Ke Za Zhi 27:935-944 